\title{
Residual Strength Degradation of a Titanium Matrix Composite Subjected to Elevated Temperature Fatigue
}

\author{
J.R. Calcaterra' and S. Mall' ${ }^{2, *}$ \\ 'Department of the Air Force, AFRL/VACS Building 63 \\ 1901 Tenth Street, Wright-Patterson AFB,OH 45433-7605, USA \\ ${ }^{2}$ Department of the Air Force, AFRL/MLLN Building 640 \\ 2950 P Street, Wright-Patterson AFB, OH 45433-7765, USA
}

\begin{abstract}
Most of the experimental fatigue studies performed on Titanium Matrix Composite (TMC) systems have subjected the test specimens to complete failure. Unfortunately, this type of investigation provides little information about the progression of damage mechanisms or the residual strength degradation of the material. To address this concern, an experimental test program was conducted on SCS-6/Ti-15-3 composite with laminate orientations of $[0]_{8},[0 / 90]_{2 s}$, and $[0 / \pm 45 / 90]_{s}$. The main goal of this research was to determine the effect of elevated-temperature $\left(427^{\circ} \mathrm{C}\right)$ fatigue on the degradation of residual strength in TMCs. Specimens were cycled until they had reached a pre-determined percentage of their fatigue life. After cycling, specimens were loaded monotonically in tension until failure. Fractography of the specimens provided information pertaining to the progression of damage mechanisms during fatigue. The laminate orientation was the primary factor for controlling the damage progression morphology as well as the residual strength degradation.
\end{abstract}

\section{INTRODUCTION}

Fiber-reinforced Titanium Matrix Composites (TMCs) have an outstanding combination of high temperature resistance and ductility. In addition, their strength and stiffness to weight ratios are far superior to most high-temperature alloys. This allows TMCs to be used with greater reliability than ceramic composites, at temperatures that preclude the use of polymeric composites or low temperature alloys. Because of their unique combination of properties, TMCs are currently considered for programs like the Integrated High Performance Turbine Engine Technology (IHPTET) initiative.

There are several classes of behavior that must be fully understood before TMCs are used in real-world applications. To address one of these behavior clasies, numerous studies have characterized different TMC fatigue properties $/ 1,2 /$. The primary goal of these investigations has typically been to quantify damage mechanisms or provide information that could help to develop a fatigue life prediction methodology. To achieve this, nearly all of the TMC fatigue literature is dedicated to tests where the specimens are cycled to failure. Although these experiments are useful, they completely ignore the problem of residual strength degradation due to fatigue. This is despite the fact that designers must know how a material's strength changes with cyclic loading. To address this lack of knowledge, recent studies have analyzed the effect of fatigue loading at different temperatures on the residual properties of TMCs with varied laminate orientations /3-5/.

Both fatigue and residual strength studies have delivered a description of the type $/ 6,7 /$ and progression

\footnotetext{
"To whom correspondence should be addressed at AFIT/ENY, BIdg. 640, 2950 P Street, Wright-Patterson Air Force Base, OH 45433-7765, USA.
} 
/8/ of damage accumulated during cycling. The damage is typically either matrix or fiber cracking, each of which can have a significant effect on residual strength. However, the wider definition of damage includes any non-reversible process such as matrix yielding, relaxation, oxidation or fiber/matrix interfacial debonding. Previous studies have shown that the amount of damage, and thus the residual strength degradation, is dependent on the parameters of the test in question /8$10 \%$. Since some trends have already been identified for unidirectional and cross-ply laminates $/ 5 /$, the goal of this research was two-fold. The first was to quantify the effect of test parameter variation on quasi-isotropic TMCs. The second was to then establish the effect of laminate orientation on TMC residual strength degradation. To this end, several quasi-isotropic specimens were fatigued under various conditions up to different points of their expected cyclic life. These specimens were then loaded to failure under quasi-static conditions to measure their residual strengths. These residual strength data were combined with cross-ply and unidirectional laminate data from previous studies $/ 4,5,11$ / to investigate the effects of lay-up. Finally, effects of damage morphology on residual strength due to laminate orientation differences were investigated.

\section{MATERIAL}

The fiber reinforced TMC, SCS-6/Ti-15-3, was used in this study. SCS-6 is a rather large silicon carbide fiber manufactured by Textron Specialty Materials Inc. The manufacturing process involves the chemical vapor deposition of silicon carbide onto a $40-\mu \mathrm{m}$ carbon substrate. The resulting fiber diameter is nominally 142 $\mu \mathrm{m}$, including a $3-5-\mu \mathrm{m}$ thick carbonaceous outer coating that is used to prevent unwanted reactions with titanium alloys during processing. Ti-15-3 is the designation for Ti-15V-3Cr-3Al-3Sn ( $w t \%)$, a metastable titanium alloy. Ti-15-3 composites are currently being considered for landing gear applications and Ti-15-3 is a good model material for beta titanium alloys.

Laminated composites plates were fabricated using the Foil-Fiber-Foil process (FFF). In the FFF process, layers of fiber are sandwiched between thin foils of the matrix material. The entire composite is then subjected to a Hot Isostatic Pressing (HIP) cycle to consolidate the material. Because each fiber layer is placed individually, any laminate orientation is possible. To maintain the correct fiber spacing, a small wire (either TitaniumNiobium (Ti-Nb) or Molybdenum (Mo)) is woven through the fibers. This wire is consolidated into the matrix during processing.

Cross-ply and quasi-isotropic specimens were machined from the composite plates using both a lowspeed diamond saw and wire Electric Discharge Machining (EDM). Quasi-isotropic specimens were straight sided and were nominally $152.4 \mathrm{~mm}$ long, $12.7 \mathrm{~mm}$ wide and $1.7 \mathrm{~mm}$ thick. Cross-ply specimens had a nearly identical geometry, with an overall width of 7.62 $\mathrm{mm}$. The fiber volume fraction $\left(V_{f}\right)$ of these specimens ranged between 0.34 and 0.36 . Quasi-isotropic specimens were machined so that the laminate orientation was either $[0 / \pm 45 / 90]_{s}$ or $[90 / \pm 45 / 0]_{s}$. The difference in laminate orientations was used to isolate any difference in residual strength degradation due to placement of the off-axis plies. Cross-ply specimens had a laminate orientation of $[0 / 90]_{2 s}$.

Unidirectional specimens, with a laminate orientation of $[0]_{8}$, were machined into a dogbone geometry using wire EDM. Specimens tested had either $V_{f}=0.35$ or 0.42 . Each specimen was nominally $152.4 \mathrm{~mm}$ long. The $V_{f}=0.42$ specimens had a $40 \mathrm{~cm}$ transition radius and a $12.7 \mathrm{~mm}$ overall width, while the $\mathrm{V}_{\mathrm{f}}=0.35$ specimens had a $116 \mathrm{~cm}$ transition radius and an overall width of $0.9 \mathrm{~cm}$. In addition, all specimens (including cross-ply) used the $\mathrm{Ti}-\mathrm{Nb}$ cross-weave material, except for the $0.42 V_{f}$ unidirectional and quasi-isotropic composites.

The specimens listed above have numerous differences in both machining and geometry. However, a previous study $/ 12 /$ has shown that there is little dependence on coupon geometry for this material. In addition, any differences in the residual strength state caused by machining would have been eliminated during the heat treatment cycle. After final machining, all specimens were wrapped in tantalum and heat treated at $700^{\circ} \mathrm{C}$ for 24 hours in an argon atmosphere. This was done to stabilize the microstructure. 


\section{EXPERIMENTAL DETAILS}

All specimens were cycled to a certain percentage of their expected fatigue lives. Tests were conducted in both strain- and load-control modes. Strain-controlled tests were conducted at a constant rate of $0.001-\mathrm{mm} /$ $\mathrm{mm} / \mathrm{sec}$, with a triangular waveform and a strain ratio $\left(R_{\varepsilon}\right)$ of -1 . Load-controlled tests were conducted at a frequency of either 5 or $10 \mathrm{~Hz}$, a sinusoidal waveform and a load ratio $\left(R_{\sigma}\right)$ of 0.05 . The compressive loads experienced in the strain-controlled tests necessitated the use of buckling guides. These guides were used in previous studies /13-15/ and were found to have negligible effect on overall fatigue properties. In addition, Pittman et al. /15/ have shown that there is no significant cyclic life effect for TMCs tested in the frequency range of this study.

All tests were conducted at $427^{\circ} \mathrm{C}$ in laboratory air. The elevated temperature was achieved with use of parabolic strip lamps and was controlled via K-type thermocouples. Two thermocouples, welded on either end of the 25.4- $\mathrm{mm}$ long gage section, were used for this purpose. When buckling guides were used, the thermocouples were spot-welded directly to them; otherwise they were welded to the specimen. The location of the thermocouples allowed for accurate thermal control over the length of the gage section while temperature controllers kept the gage section to within $\pm 1^{\circ} \mathrm{C}$ of the set point $\left(427^{\circ} \mathrm{C}\right)$.

Specimens were tested on either a servo-hydraulic or servo-electric, screw-driven, test frame. The load capacity of each frame was $100 \mathrm{kN}$. All specimens were gripped with hydraulic, water-cooled, friction grips and were tabbed as necessary to avoid unwanted stress concentrations. Strain data for all tests was obtained with the use of a ceramic-rod, high-temperature, contact extensometer. The data from this device was also used for control input in the strain-controlled tests. In all tests, the extensometer was held on with the use of a spring-loaded arm. The gage length for the extensometer was $12.7 \mathrm{~mm}$ with a range of +0.20 to $-0.10 \mathrm{~mm} /$ $\mathrm{mm}$. The details and results of all tests used in this study are given in Table 1.

As noted from Table 1, relatively few specimens were tested compared to a typical fatigue study. There was very little data that was reproduced and several specimens had different cross-weave materials. The lack of repeated data is due to the cost of TMC specimens, while the use of different cross-ply material is due to different manufacturing processes. The Mo cross-weave has previously been shown to cause preferential cracking $/ 8 /$. However, in this study there was no significant difference in the cyclic life between the specimens that used Mo and those that used Ti-Nb. In addition, the monotonic tests used to determine ultimate strength are not listed. At least two tests were conducted for each value of ultimate strength. The scatter of these tests was typically $\pm 20 \%$ of the final value.

\section{RESULTS AND DISCUSSION}

\section{Mechanical Results}

\section{Unidirectional Laminate}

A previous study has shown that residual strength degradation is primarily dependent on cyclic life $/ 5 /$. In other words, any apparent differences in residual strength degradation due to varying test parameters such as test control mode, stress ratio or test frequency are accounted for as long as the degradation is plotted against a percentage of cyclic life. To illustrate this, the residual strength degradation based on cyclic life is plotted in Figure la with the normalized residual strength plotted against percent life in Figure $\mathrm{lb}$. The strength axis is normalized by the appropriate ultimate strength. For strain control tests, the ultimate strength value at $100 \%$ life was calculated by averaging the peak stresses recorded in the last three cycles prior to failure It is apparent from this figure that normalizing both axes accounts for differences in all test parameters, including frequency, $R$ ratios and control modes, Table 1 . The overall trend of strength degradation in the material is non-linear. It maintains at least $90 \%$ of its virgin strength up to $75 \%$ life, followed by a considerable decrease in residual strength up to $100 \%$ life.

\section{Cross-Ply Laminate}

Figure 2a and Figure $2 \mathrm{~b}$ show the cycle-based and normalized cycle-based (or percent life-based) residual strength degradation for $[0 / 90]_{2 s}$ laminates, respectively. 
Table 1

Summary of all tests used in current study

\begin{tabular}{|c|c|c|c|c|c|c|c|c|}
\hline Lay-up & $V_{f}$ & $\begin{array}{l}\text { Test } \\
\text { Control } \\
\text { Mode }\end{array}$ & R Ratio & $\begin{array}{l}\text { Freq. } \\
(\mathrm{Hz})\end{array}$ & $\begin{array}{c}\text { Max Stress } \\
\text { (MIPa) or } \\
\text { Strain (\%) }\end{array}$ & $\begin{array}{c}\text { Residual } \\
\text { Strength } \\
\text { (MPa) }\end{array}$ & Last Cycle & Ref. \\
\hline$\left[\left.0\right|_{8}\right.$ & 0.35 & Load & -- & - & -- & $1.386^{1}$ & -- & {$[11]$} \\
\hline$[0]_{8}$ & 0.35 & Load & 0.05 & 10 & 900 & 1.325 & 7.645 & [11] \\
\hline$[0]_{8}$ & 0.35 & Load & 0.05 & 10 & 900 & 1.287 & 15.284 & {$[11]$} \\
\hline$\left[\left.0\right|_{8}\right.$ & 0.35 & Load & 0.05 & 10 & 900 & $900^{-}$ & 20.244 & {$[11]$} \\
\hline$\left[\left.0\right|_{8}\right.$ & 0.35 & Load & 0.05 & 10 & 900 & $900^{\circ}$ & 30.561 & {$[11]$} \\
\hline $10 /\left.90\right|_{25}$ & 0.35 & Load & -- & -- & -- & 996 & -- & {$[11]$} \\
\hline$[0 / 90]_{2 s}$ & 0.35 & Load & -- & -- & -- & $844^{1}$ & -- & [11] \\
\hline$[0 / 90]_{2 s}$ & 0.35 & Load & 0.05 & 10 & 450 & 768 & 6.598 & [11] \\
\hline$[0 / 90]_{2 s}$ & 0.35 & Load & 0.05 & 10 & 450 & 859 & 8,004 & [11] \\
\hline$[0 / 90]_{2 s}$ & 0.35 & Load & 0.05 & 10 & 450 & 663 & 10.692 & [11] \\
\hline$[0 / 90]_{2 s}$ & 0.35 & Load & 0.05 & 10 & 450 & $450^{2}$ & 17,023 & [11] \\
\hline$[0 / 90]_{2 s}$ & 0.35 & Load & 0.05 & 5 & 300 & 767 & 50,010 & [11] \\
\hline$[0 / 90]_{2 s}$ & 0.35 & Load & 0.05 & 5 & 300 & 512 & 80,009 & [11] \\
\hline$[0 / 90]_{2 s}$ & 0.35 & Load & 0.05 & 5 & 300 & $300^{2}$ & 94,153 & [11] \\
\hline$[0 / 90]_{2 s}$ & 0.35 & Load & 0.05 & 5 & 300 & 481 & 100.011 & [11] \\
\hline$[0 / 90]_{2 s}$ & 0.35 & Load & 0.05 & 5 & 300 & $300^{2}$ & 186,003 & [11] \\
\hline$[0]_{8}$ & 0.42 & Strain & -- & -- & -- & $1,428^{3}$ & -- & {$[4]$} \\
\hline$[0]_{8}$ & 0.42 & Strain & -1 & 0.0625 & 0.4 & $563^{2}$ & 10,630 & [4] \\
\hline$[0]_{8}$ & 0.42 & Strain & -1 & 0.083 & 0.3 & $728^{2}$ & 90,069 & {$[4]$} \\
\hline$[0]_{8}$ & 0.42 & Strain & -1 & 0.083 & 0.3 & 1,249 & 48,464 & [4] \\
\hline$[0]_{8}$ & 0.42 & Strain & -1 & 0.0625 & 0.4 & 1,310 & 5,315 & {$[4]$} \\
\hline$[0]_{8}$ & 0.42 & Strain & -1 & 0.0625 & 0.3 & 1,232 & 67,552 & {$[4]$} \\
\hline$[0]_{8}$ & 0.42 & Strain & -1 & 0.083 & 0.4 & 1,673 & 7,973 & [4] \\
\hline$[0 / 90]_{2 s}$ & 0.35 & Strain & -1 & 0.1 & 0.25 & $240^{2}$ & 70,000 & {$[5]$} \\
\hline$[0 / 90]_{2 s}$ & 0.35 & Strain & -1 & 0.083 & 0.3 & $318^{2}$ & 47,700 & {$[5]$} \\
\hline$[0 / 90]_{25}$ & 0.35 & Strain & -1 & 0.0625 & 0.4 & $381^{2}$ & 12,500 & {$[5]$} \\
\hline$[0 / 90]_{25}$ & 0.35 & Strain & -1 & 0.083 & 0.3 & 865 & 5,510 & {$[5]$} \\
\hline$[0 / 90]_{2 s}$ & 0.35 & Strain & -1 & 0.083 & 0.3 & 852 & 11,000 & [5] \\
\hline$[0 / 90]_{25}$ & 0.35 & Strain & -1 & 0.083 & 0.3 & 736 & 16,485 & [5] \\
\hline$[0 / 90]_{2 s}$ & 0.35 & Strain & -1 & 0.083 & 0.3 & 609 & 35,325 & {$[5]$} \\
\hline$[0 / 90]_{2 s}$ & 0.35 & Strain & -1 & 0.0625 & 0.4 & 670 & 6,250 & [5] \\
\hline$[0 / 90]_{2 s}$ & 0.35 & Strain & -1 & 0.0625 & 0.4 & 510 & 9,375 & {$[5]$} \\
\hline$[0 / 90]_{2 s}$ & 0.35 & Strain & -1 & 0.0625 & 0.4 & 761 & 3,125 & [5] \\
\hline$[0 / 90]_{25}$ & 0.35 & Strain & -1 & 0.1 & 0.25 & 647 & 35,000 & [5] \\
\hline$[0 / 90]_{2 s}$ & 0.35 & Strain & -1 & 0.1 & 0.25 & 524 & 52,500 & [5] \\
\hline$[0 / \pm 45 / 90]_{\mathrm{s}}$ & 0.35 & - & -- & -- & -- & 780 & - & {$[16]$} \\
\hline$[0 / \pm 45 / 90]_{\mathrm{s}}$ & 0.35 & Strain & -1 & 0.083 & 0.3 & 280 & $30,960^{2}$ & \\
\hline$[0 / \pm 45 / 90]_{s}$ & 0.35 & Strain & -1 & 0.083 & 0.3 & 472.5 & 23,001 & 5 \\
\hline$[0 / \pm 45 / 90]_{\mathrm{s}}$ & 0.35 & Strain & -1 & 0.083 & 0.3 & 633.2 & 15,090 & \\
\hline$[90 / \pm 45 / 0]_{5}$ & 0.35 & Strain & -1 & 0.083 & 0.3 & 240.7 & $43,312^{2}$ & 5 \\
\hline$[90 / \pm 45 / 0]_{5}$ & 0.35 & Strain & -1 & 0.083 & 0.3 & 344.9 & 32,503 & \\
\hline$[90 / \pm 45 / 0]_{\mathrm{s}}$ & 0.35 & Strain & -1 & 0.083 & 0.3 & 413.2 & 21,585 & \\
\hline$[0 / \pm 45 / 90]_{5}$ & 0.35 & Strain & -1 & 0.0625 & 0.4 & 335 & $6,961^{2}$ & \\
\hline$[0 / \pm 45 / 90]_{s}$ & 0.35 & Strain & -1 & 0.0625 & 0.4 & 552.9 & 5,221 & 5 \\
\hline$[0 / \pm 45 / 90\}_{s}$ & 0.35 & Strain & -1 & 0.0625 & 0.4 & 492.5 & 3,418 & \\
\hline
\end{tabular}

1. Load-controlled tensile test. Constant stress rate of $15 \mathrm{MPa} / \mathrm{sec}$

2. Full-term fatigue test used to normalize cyclic life

3. Average of two strain-controlled tensile tests. Constant strain rate of $0.001-\mathrm{mm} / \mathrm{mm} / \mathrm{sec}$

4. Average of three strain-controlled tensile tests. Constant strain rate of $0.001-\mathrm{mm} / \mathrm{mm} / \mathrm{sec}$

5. Tests conducted for this study 


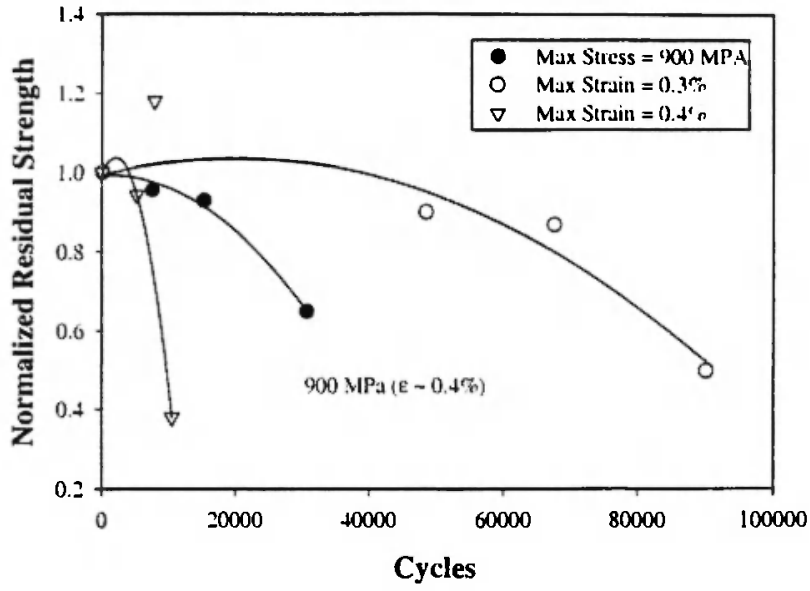

(a)

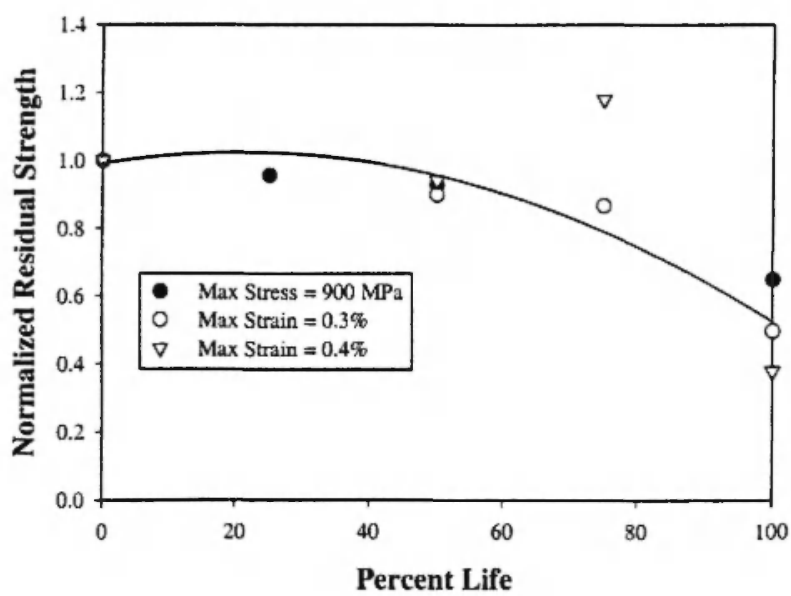

(b)

Fig. 1: Normalized residual strength of $[0]_{8}$ SCS-6/ Ti-15-3 subjected to fatigue under load- and strain-control modes plotted against (a) cyclic life and (b) percent life.

This shows the data from both load- and strain-control modes, with the corresponding differences in frequency, Table 1. Similar to Figure $\mathrm{lb}$, the normalization accounts for all test parameter variances in strength degradation. However, it is apparent that there is much more scatter in the cross-ply laminate data than that for the unidirectional material. This scatter has been previously noted $/ 13,16,17 /$ and is typically assumed to be due to rapid damage progression caused by off-axis debonds $/ 17 /$ in the cross-ply laminate. The variability in the residual strength degradation was also attributed

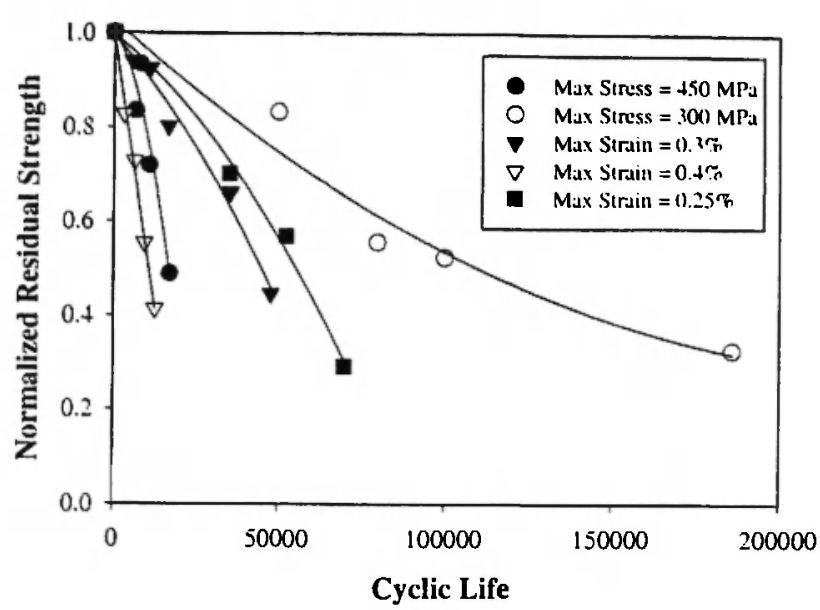

(a)

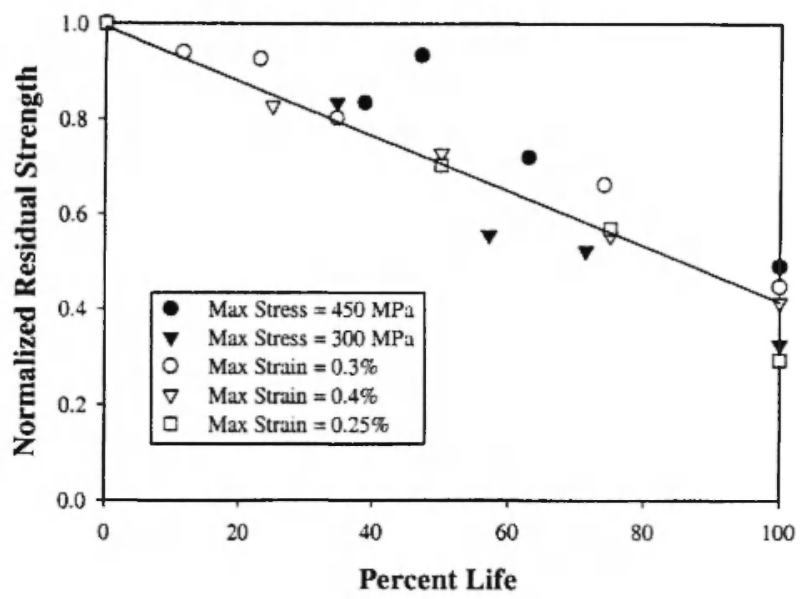

(b)

Fig. 2: Normalized residual strength of $[0 / 90]_{25}$ SCS-6/ Ti-15-3 during fatigue under load- and straincontrol modes plotted against (a) cyclic life and (b) percent life.

to the inconsistency of the interfacial shear strength $/ 18$, 19. In contrast to the unidirectional material, the crossplay laminate's strength degradation occurs at a nearly constant rate over its fatigue life. The degradation starts from the onset of cycling and continues linearly until final fatigue failure.

\section{Quasi-Isotropic Laminate}

Since all the quasi-isotropic laminate data used in this study were developed in strain control, there is no direct observation of the effect of control mode, fatigue 
stress ratio or frequency on the residual strength degradation of the quasi-isotropic laminate. However, based on trends from the unidirectional and cross-ply laminates, it can be safely postulated that normalized residual strength of quasi-isotropic laminate would also be independent of control mode, stress ratio and frequency. Figure $3 a$ shows the normalized residual strength degradation for quasi-isotropic SCS/Ti-15-3 based on the number of cycles. This figure shows a clear layering between the specimens tested at 0.003 maximum strain and those tested at 0.004 maximum strain. This layering is due simply to the reduced cyclic life of the higher strain test. Using an ultimate strength

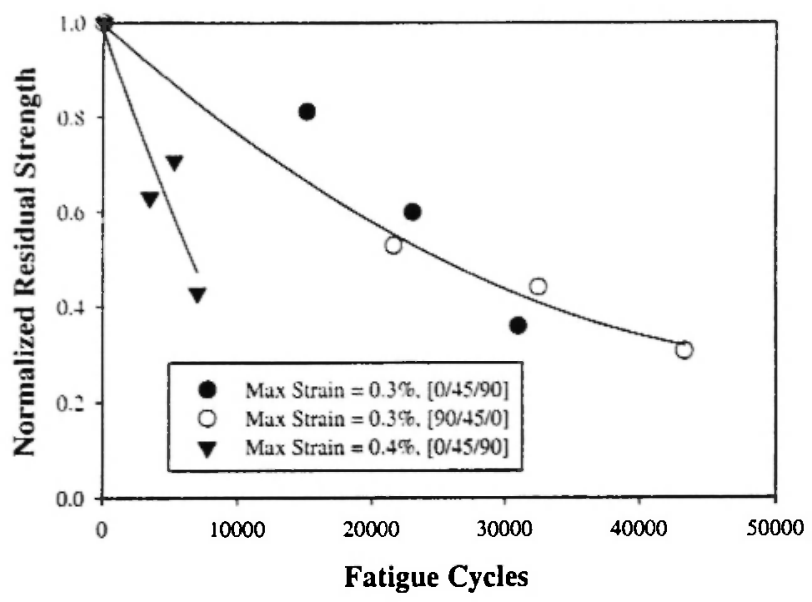

(a)

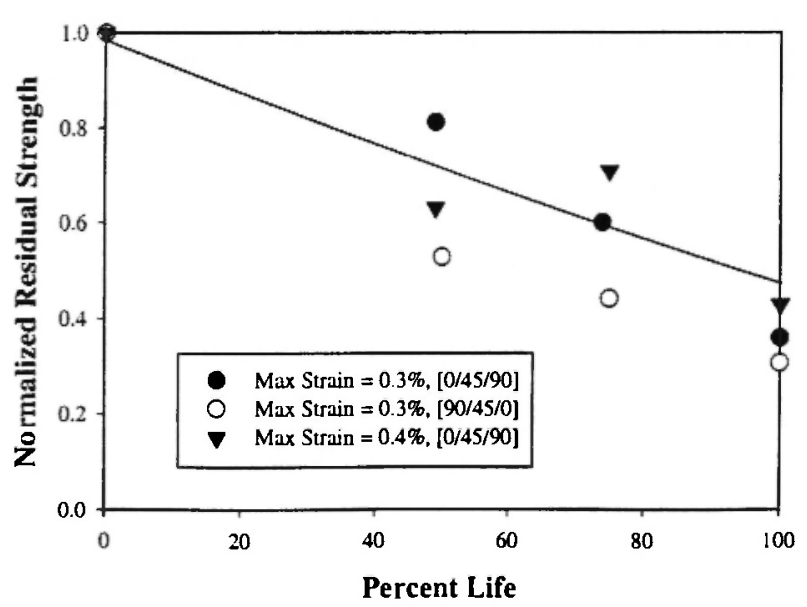

(b)

Fig. 3: Normalized residual strength for quasiisotropic SCS-6/Ti-15-3 plotted against (a) applied cycles and (b) percent life. value of $780 \mathrm{MPa} / 20$ /, the residual strength values were normalized and plotted against percent life. This is illustrated in Figure 3b. Comparing both figures shows that the previous result concerning the usefulness of axis normalization $15 /$ in describing the residual strength degradation of TMCs is applicable regardless of laminate orientation.

As illustrated in Figure 3b, there is a scatter in the data similar to the cross-ply laminate, Figure $2 b$. This may be again attributed to the susceptibility of more random damage due to the presence of many off-axis plies. Further, there is scatter between the data generated for the $[90 / \pm 45 / 0]_{\mathrm{s}}$ specimens and the $[0 / \pm 45 / 90]_{\mathrm{s}}$ specimens. Based on the limited amount of data available, it is difficult to say whether this cyclic life difference is actually a lay-up-based material characteristic or simply test scatter. While it is most likely due to test scatter, as commonly seen in fatigue studies, there is a possibility that it also may be due to the fact that quasi-isotropic laminates with $[90 / \pm 45 / 0]_{\mathrm{s}}$ orientations had longer lives than those with $[0 / \pm 45 / 90]_{s}$ lay-ups. Finally, the degradation of strength in the quasi-isotropic laminate laminates occurs earlier in life than the cross-ply laminate.

\section{Laminate Comparison}

A comparison of the residual strength degradation for all laminate orientations is shown in Figure 4. For clarity, only the strain-controlled data is presented. As illustrated in the figure, the normalization does not account for the differences due to laminate orientation. Both laminates with off-axis plies degrade at a greater rate, starting during early cycling, and continue to degrade until failure. However, the degradation rate for each orientation is different. The crosss-ply material retains about $70 \%$ of strength up to $50 \%$ life and $50 \%$ strength up to $75 \%$ life. In contrast, the quasi-isotropic material retains between 50 and $75 \%$ strength up to $50 \%$ life and between 35 and $65 \%$ strength at $75 \%$ life. Although the maximum values in the scatter band of data for each material are the same, the minimum values for the quasi-isotropic material are much lower. One of the most noticeable features from this comparison is that the quasi-isotropic laminate at its half-life point may retain less than half of the residual strength. This means that the maximum overload this material could 


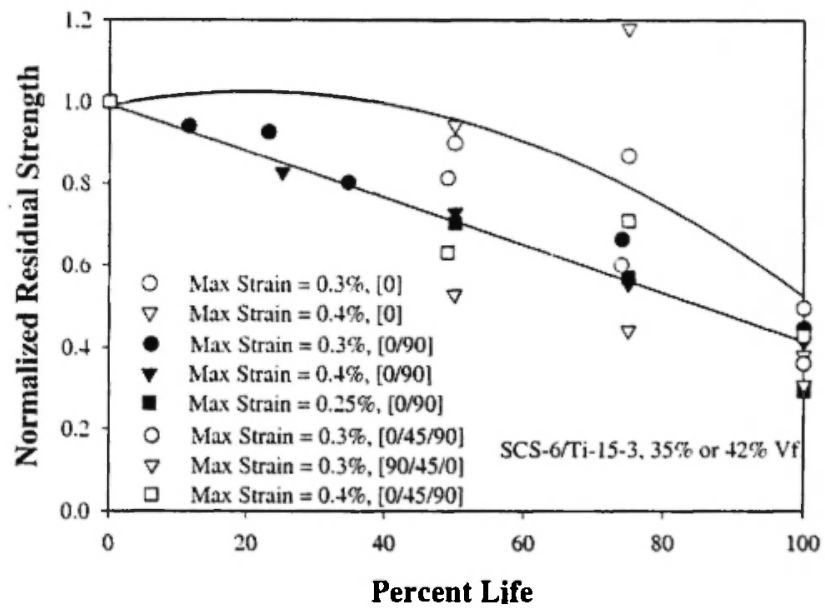

Fig. 4: Comparison of normalized residual strength for all laminate orientations.

withstand during its service life is quite small. This is not the case for the cross-ply material.

In contrast to both off-axis laminates, the unidirectional laminates experienced very little degradation in the first $75 \%$ of life. A sharp drop off in strength was experienced during the last $25 \%$ of life. The sharp drop off is due to the fact that the fatigue lives of the unidirectional material are dominated by damage initiation, with growth only becoming significant in the last stage of life. This is unlike laminates with off-axis plies where damage not only initiates but also grows immediately from the start of cycling until the end of fatigue life. Further, the degradation of residual strength in the cross-ply and quasi-isotropic composites is at least three times that of the unidirectional composites. There are no mechanical parameters that can account for this difference in strength degradation. Because of this, the difference in residual strength reduction trends may be attributed solely to the difference in damage mechanism development. The difference in damage morphology between unidirectional composites and those with off-axis plies will be described in more detail in the following section.

It should be noted that using the variance of $\pm 20 \%$ in the ultimate strength as a scatter value, the error bands of the cross-ply and quasi-isotropic laminates could be made to overlap. However, the majority of the data for the cross-ply material fall very close to the respective trend line, and three repeats were performed for the quasi-isotropic laminates at each cyclic life level. Because of this, the effects of scatter were assumed to be minimal.

\section{Microscopic Results}

\section{Unidirectional Laminate}

The damage mechanisms associated with the tensile fatigue cycling of unidirectional laminates are well documented $15-10 /$. Further, the addition of a compressive portion of the fatigue cycle did not develop significant additional damage mechanisms $/ 5 /$. Finally, previous studies $21 /$ have illustrated the fact that post mortem fiber damage analysis is nearly impossible. Because of these facts, the discussion of damage development will be limited to matrix behavior, primarily matrix cracking.

Although the damage development in unidirectional laminates has been previously described in detail $/ 5 /$, it is important to present an overview of the results for the sake of comparison. The amount of cracking on the fracture surface of these specimens increases with both cycling and the value of applied maximum strain. The morphology of the damage also changes with these parameters. At lower values of applied strain, there is one dominant crack plane while at higher values of maximum strain there are several crack planes, as illustrated in Figure 5. A schematic representation of single and multiple crack planes is illustrated in Figure 6. The morphological difference of the damage, along with the amount, will have an effect on the residual strength degradation, i.e., multiple planes at higher values of applied strain provide higher residual strength or no residual strength degradation. On the other hand, a single plane at lower strain values has a noticeable effect on the residual strength.

The microscopic examination also identified three main matrix crack initiation sites for the unidirectional composite. These sites are the machined surface, the fiber/matrix interface and the location of the crossweave material. For the cross-weave material, the Mo wire caused more crack initiation than the $\mathrm{Ti}-\mathrm{Nb}$ material. A microphotograph illustrating two of these crack initiation sites is shown in Figure 7. It should be noted, however, that there was rarely any crack initia- 




(a)

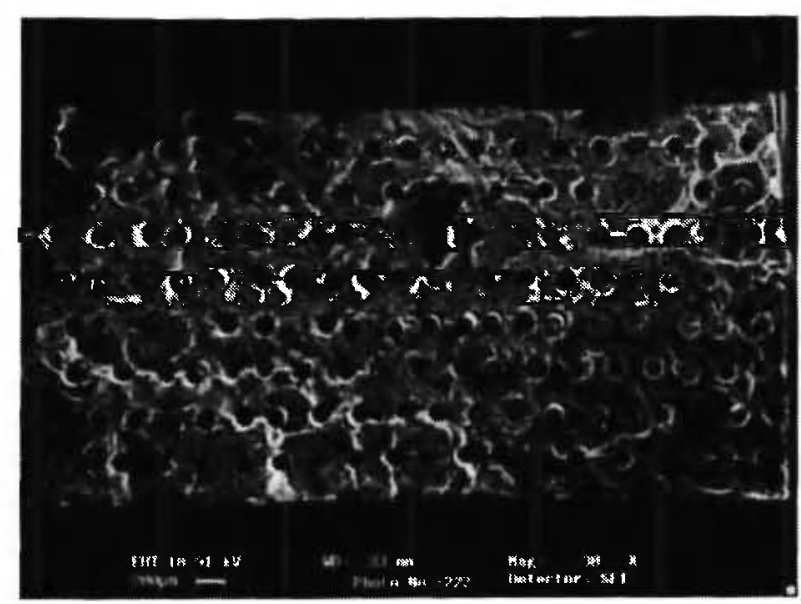

(b)

Fig. 5: Comparison of damage morphology for SCS-6/Ti-15-3 tested at (a) $0.0025 \mathrm{~mm} / \mathrm{mm}$ maximum under applied strain and (b) 0.0055 $\mathrm{mm} / \mathrm{mm}$ maximum applied strain.

tion by $50 \%$ life and approximately only $10 \%$ cracked area was found at $75 \%$ of fatigue life. Finally, once cracks had initiated, they grew very slowly due to the large number of bridging fibers parallel to the applied load direction and produced minimal degradation of residual strength $/ 22 \%$.

\section{Cross-Ply Laminate}

The fracture surfaces of the cross-ply specimens are quite different from those of the unidirectional specimens. The main difference is due to the near-

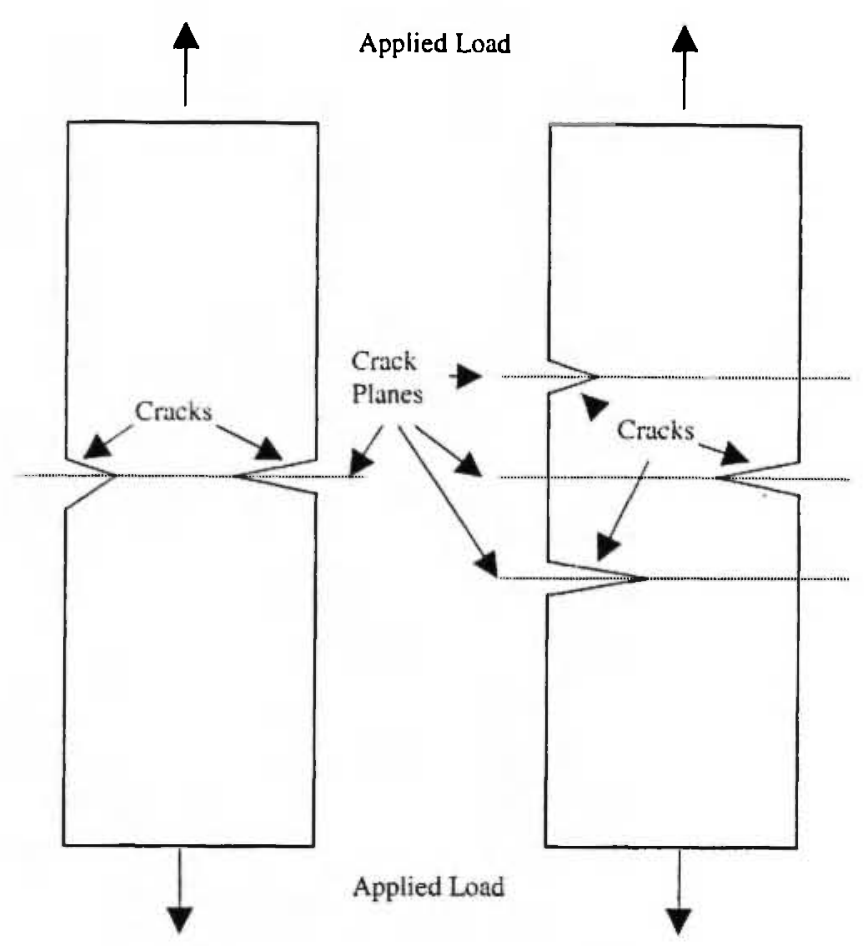

Single Crack Plane

Multiple Crack Planes

Fig. 6: Illustration of multiple cracks interacting on different crack planes.

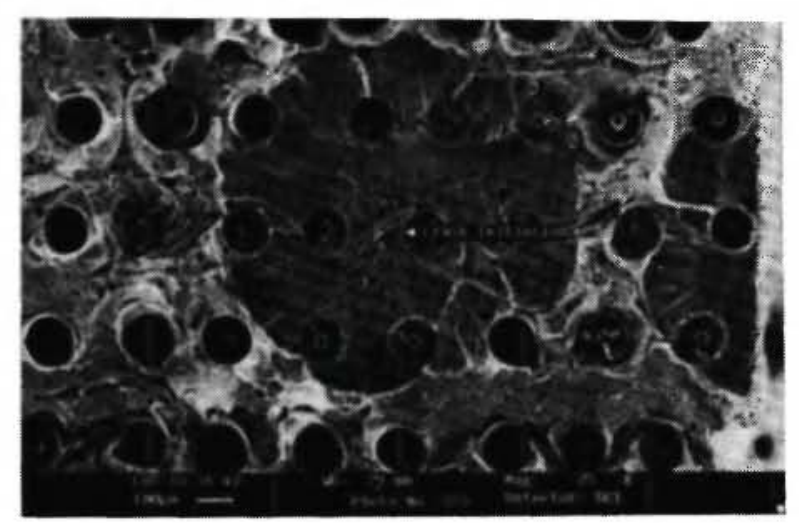

Fig. 7: Two crack initiation sites at $75 \%$ life for SCS-6/Ti-15-3 $[0]_{8}$ specimen.

immediate crack initiation caused by off-axis fiber/ matrix debonds with applied loading. The progression of damage in the cross-ply material is illustrated in Figure 8. In this figure, it is evident that significant 


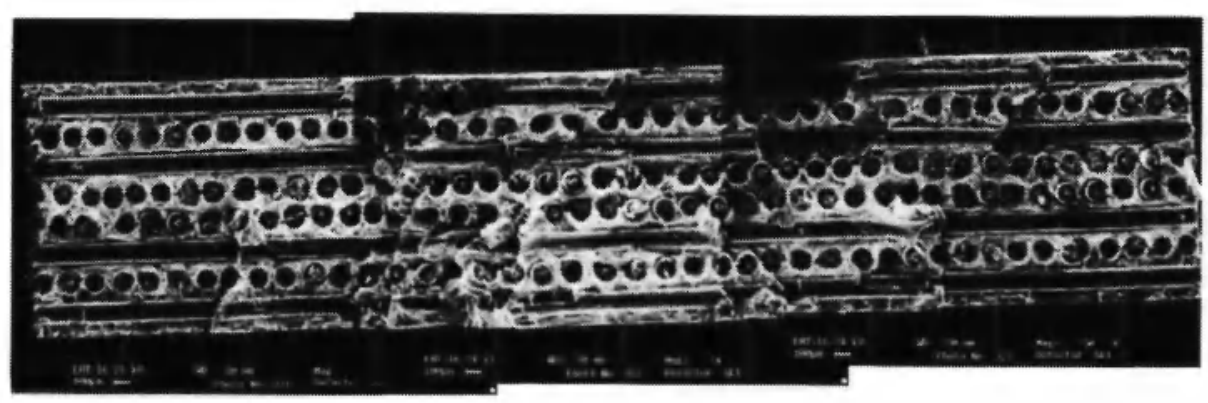

(a)

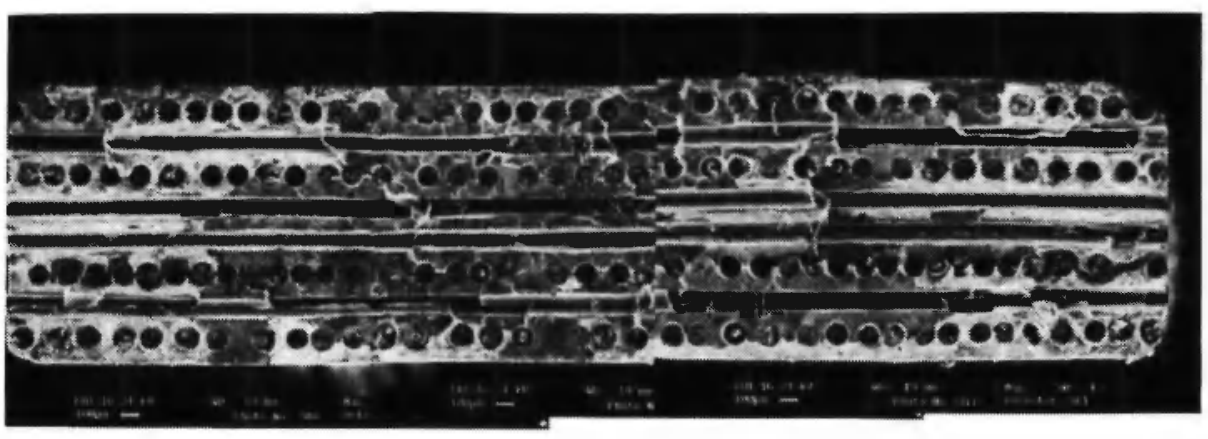

(b)

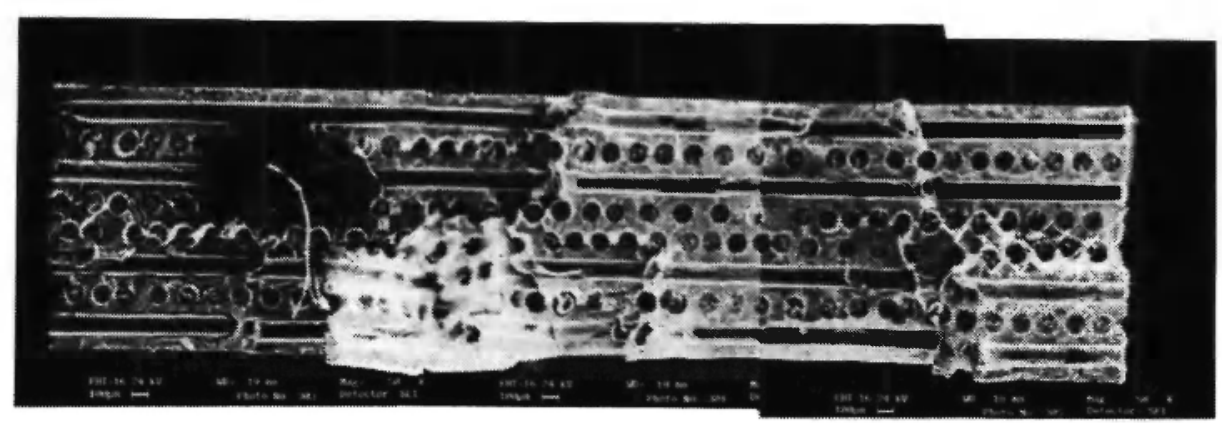

(c)

Fig. 8: Specimens tested with a maximum applied strain of $0.3 \%$ at (a) $12 \%$, (b) $25 \%$ and (c) $75 \%$ of expected cyclic life. (Strain-control)

cracking is already initiated by $12 \%$ of cyclic life. The cracked area eventually grows, with cycling, until the matrix cracks reach the $0^{\circ}$ fibers. Another feature of the microphotographs seen in Figure 8 is that the widest part of the off-axis fiber is located on the fracture surface. This results in a fiber area fraction on the failure surface of approximately $50 \%$. This is significant because the amount of cracking necessary to fail the specimen completely can be quite different from what would be indicated when the fiber volume fraction alone is used to calculate failure. The early crack initiation and steady growth throughout cyclic life correlates well with the trends in residual strength degradation. The overall trend of increasing damage and increasing number of crack planes as seen for the unidirectional material holds true for the cross-ply material as well. 


\section{Quasi-Isotropic Laminates}

The damage development in the quasi-isotropic specimens has many characteristics in common with the cross-ply material. The primary commonalties are that the $90^{\circ}$ fibers debond from the matrix early in cyclic life and that the damage propagation from these debonds controls the location of failure. There is also a similarity to the $0.42 \mathrm{~V}_{\mathrm{f}}$ unidirectional specimens because the Mo cross-weave material again proves to be a significant source of crack growth. However, there are several major differences between the quasi-isotropic laminates and all other orientations.

The first difference is that the general trend for crack plane development seen in both the unidirectional and cross-ply material does not hold true for the quasiisotropic laminates. In general, when quasi-isotropic specimens are fatigued to failure, there is only a small amount of cracking that is not in the dominant plane, as seen in Figure 9a. However, when these specimens are monotonically pulled to failure after a certain portion of the cyclic life, there are typically several large crack planes, as seen in Figure $9 \mathrm{~b}$. This occurs regardless of applied maximum strain value. In addition, the amount of cracking seen on the fracture surface does not increase greatly during the later stages of cyclic life. This is illustrated by the comparison of fracture surfaces of $100 \%$ and $50 \%$ of fatigue life specimens shown in Figure 10. A third difference between these laminates and cross-ply specimens is that the cracks that emanate from the $90^{\circ}$ plies do not necessarily reach the $0^{\circ}$ plies. There are several instances where the cracks that grew into the $0^{\circ}$ plies initiated from the fiber/matrix interface of the $\pm 45^{\circ}$ plies, as seen in Figure 11. Crack initiation from all off-axis plies essentially gives the quasiisotropic material more damage initiation sites than the cross-ply composite.

The different damage morphology of the quasiisotropic composite leads to a different failure mechanism. Whereas crack growth or initiation seems to be the main factor in failure of unidirectional and cross-ply composites, the quasi-isotropic material seems to be more affected by the joining of different damage sites (which can be considered a specific type of crack growth). From the residual strength tests, it is apparent that the material has a large amount of cracking by $50 \%$ of fatigue life. This is supported by the fact that all off-

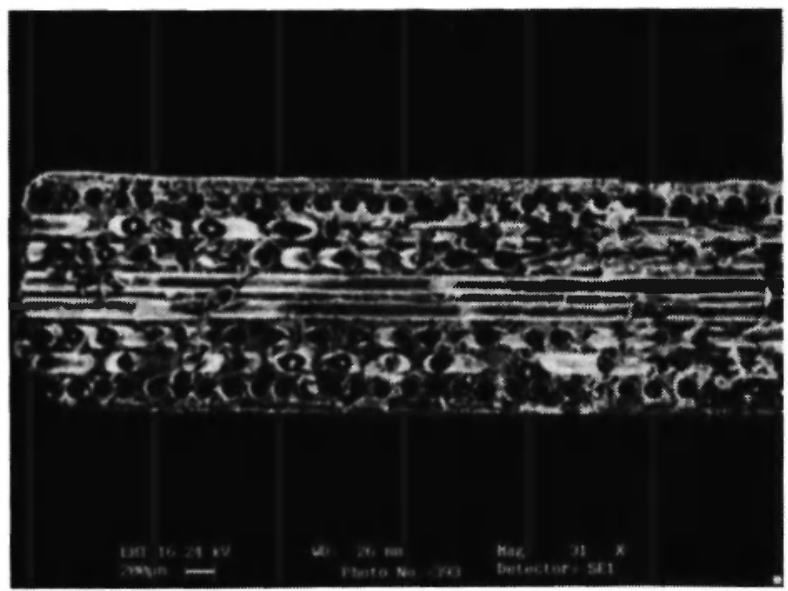

(a)

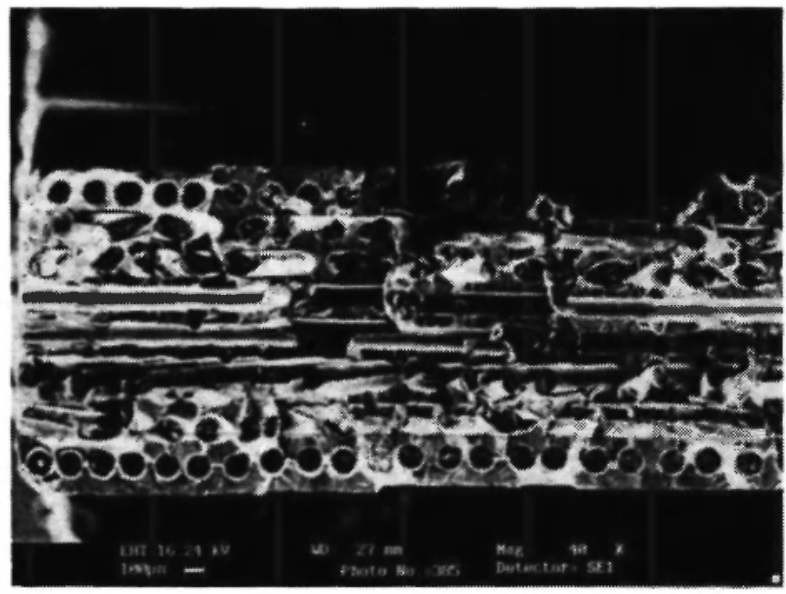

(b)

Fig. 9: Overview of failure surfaces for $[0 / \pm 45 / 90]_{2 s}$ after (a) full-term fatigue life and (b) $75 \%$ fatigue life at $0.003 \mathrm{~mm} / \mathrm{mm}$ maximum applied strain.

axis plies, not just the $90^{\circ}$ plies, result in significant crack initiation and growth. However, the cracks that develop by $50 \%$ life have not connected with cracks on other planes. Linking of the dominant crack planes and different cracks on the same plane results in the ultimate failure of the composite. This is why the full-term fatigue tests typically have fewer failure planes than the residual strength tests.

There is little difference in the damage morphology 


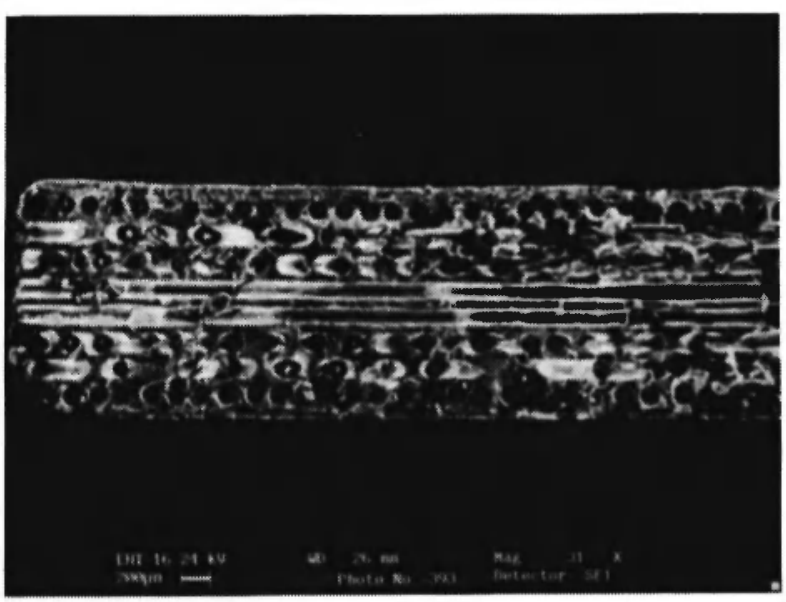

(a)

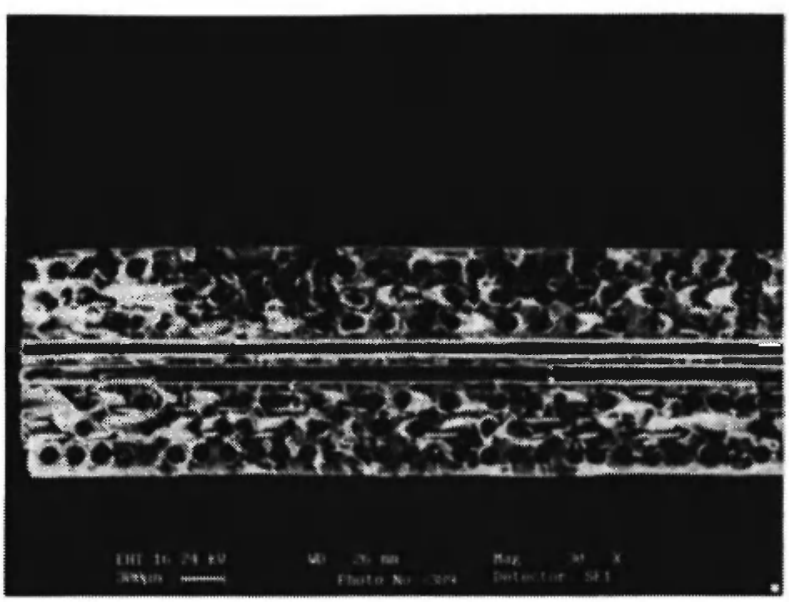

(b)

Fig. 10: Comparison of amount of matrix cracking on fracture surface for (a) full-term fatigue and (b) $50 \%$ life specimens fatigued at $0.004 \mathrm{~mm} /$ mm maximum strain.

between the $[0 / \pm 45 / 90]_{\mathrm{s}}$ and the $[90 / \pm 45 / 0]_{\mathrm{s}}$ specimens. It was thought that moving the $0^{\circ}$ degree fibers to the center of the specimen thickness may shield them from the two crack initiation mechanisms; the off-axis debonding and the machined surface. However, as seen above, all off-axis plies, not just the $90^{\circ}$ plies, contribute to the total number of damage initiation sites. Therefore, moving the $0^{\circ}$ fibers to the center of the laminate does not make any difference in the degradation of residual

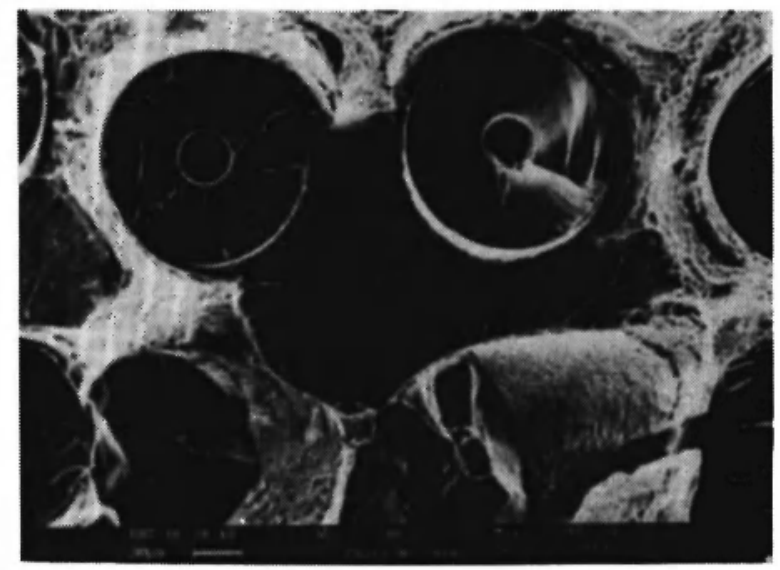

Fig. 11: Crack initiation from $45^{\circ}$ fiber/matrix interface.

strength. Because of this, the difference in residual strength degradation due to reversed laminate orientations is due to scatter (Figure $3 b$ ).

\section{CONCLUSIONS}

The residual strength degradation of TMCs depends primarily on the percentage of cyclic life that has been used. Residual strength degradation characteristics are also dependent on the fiber stacking sequence of the laminate. The orientation-based differences in residual strength degradation are due to changes in damage morphology, damage initiation sites and failure mechanisms.

In general, the residual strength of these composites degrades faster with cycling when off-axis plies are added. This is due to the fiber/matrix debonding and subsequent crack initiation that originates from these plies. Microscopic inspection revealed that this occurs from off-axis plies with fiber orientations of $90^{\circ}$ and $45^{\circ}$ to the load path. In addition, mechanical results showed that unidirectional composites retain nearly all of their strength up to $50 \%$ life, while the cross-ply specimens held only $70 \%$ strength up to this point and that the quasi-isotropic laminates held between 50 and $75 \%$ strength. This is a significant result for designers who wish to use this material because it means the residual strength testing is required for any laminate with 
numerous off raxis plies before that laminate can be used in actual service. In addition, any researchers attempting to develop a predictive methodology for residual strength degradation in TMCs should account for the change in damage morphology and failure mechanisms.

\section{ACKNOWLEDGMENT}

The authors wish to thank the Air Force Office of Scientific Research (AFOSR) as well as the Propulsion Directorate (Ted Fecke) of the Air Force Research Laboratory (AFRL) for their support of this work. They would also like to thank Mr. Mark Derriso of the AFRL's Air Vehicles Directorate for lending his significant testing expertise to the completion of this program.

\section{REFERENCES}

1. S. Mall and T. Nicholas (Editors), Titanium Matrix Composites: Mechanical Behavior, Technomic Publishing Co., 1997.

2. J.R. Calcaterra and W.S. Johnson, "A comparison of damage mechanisms for SCS-6/Timetal $21 \mathrm{~S}$ subjected to various thermomechanical fatigue cycles", Proceedings of the American Society for Composites: Tenth Technical Conference, october 18-20, 1995; pp. 205-214.

3. C.G. Schmidt, C.H. Kanazawa and D.A. Shockey, "Residual strength of a thermomechanically fatigued TIMETAL 21S/SCS-6 composite", Journal of Materials Engineering and Performance, 4(5), 624-626 (1995).

4. J.R. Calcaterra, S.C. Coghlan and S. Mall, "Degradation of residual strength in SCS-6/Ti-15-3 due to fully reversed fatigue", Metallurgical and Materials Trans., 30A, 307-313 (1999).

5. J.R. Calcaterra and S. Mall, "Strength degradation during fatigue of unidirectional and cross-ply SCS6/Ti-15-3", International Journal of Fatigue, 21, 215-223 (1999).

6. W.S. Johnson, J.L. Miller and M. Mirdamadi, "Fractographic interpretation of failure mechanisms in titanium matrix composites", Materials
Science and Engineering, A200, 78-88 (1995).

7. M. Mirdamadi, J.G. Bakuckas and W.S. Johnson, "Mechanisms of strain accumulation in titanium matrix composites at elevated temperatures", Mechanics of Composite Materials - Nonlinear Effects, American Society of Mechanical Engineers, AMD , 159, 245-252 (1993).

8. M.G. Castelli, "Thermomechanicaal fatigue damage/failure mechanisms in SCS-6/Timetal $21 \mathrm{~S}$ [0/90] $]_{3}$ composite", Composites Engineering, 4 (9), 931-946 (1994).

9. S.M. Jeng, P.C. Wang and J.-M. Yang, "Fatigue damage evolution and degradation of mechanical properties in silicon-carbide (SiC) fiber-reinforced titanium matrix composites", Life Prediction Methodology for Titanium Matrix Composites, ASTM STP 1253, W.S. Johnson, J.M. Larsen and B.N. Cox (Editors), American Society for Testing and materials, 1996; pp. 377-394.

10. F.W. Zok, S.J. Connell and Z.-Z. Du, "Fatigue maps for titanium matrix composites", Life Prediction Methodology for Titanium Matrix Composites, ASTM STP 1253, W.S. Johnson, J.M. Larsen and B.N. Cox (Editors), American Society for Testing and materials, 1996; pp. 432-460.

11. D.D. Robertson and S. Mall, "Strength degradation in titanium matrix composites exposed to fatigue at elevated temperature", Proceedings of the Eleventh International Conference on Composite Materials, Vol. Ill, July 14-18 1997; pp. 365-373.

12. J. Gayda and T.P. Gabb, "Effect of heating mode and specimen geometry on fatigue properties of a metal matrix composite", Proceedings of the $3^{\text {rd }}$ HiTemp Conference, Paper 31, 1990.

13. S. Mall and E.A. Boyum, "Fatigue behavior of a cross-ply titanium matrix composite with tensile and zero mean load at elevated temperature", Journal of Composites Technology and Research, 19(2), 49-58 (1997).

14. B.P. Sanders, S. Mall and S.C. Jackson, "Load ratio effects on fatigue of titanium matrix composites at elevated temperature", International Journal of Fatigue, 21, 121-134 (1999).

15. R.N. Pittman, B.P. Sanders and S. Mall, "Frequency and temperature effects on fatigue behavior of a unidirectional titanium matrix composite", 
Composites Science and Technology, 59, 583-591 (1999).

16. K.A. Hart and S. Mall, "Thermomechanical fatigue behavior of a quasi-isotropic SCS-6/Ti-15-3 metal matrix composite", ASME Journal of Engineering Materials and Technology, 117(1), 109-117 (1995).

17. B.A. Lerch and G. Halford, "Effects of control mode and R-ratio on the fatigue behavior of a metal matrix composite", Materials Science and Engineering, A200, 47-54 (1995).

18. B.S. Majumdar and G.M. Newaz, "Constituent damage mechanisms in MMCs under fatigue loading, and their effects on fatigue life", Materials Science and Engineering, A200, 114-129 (1995).

19. J.G. Bakuckas and W.S. Johnson, “Application of fiber bridging models to fatigue crack growth in unidirectional titanium matrix composites", Journal of Composites Technology \& Research, 15(3), 242-255 (1993).

20. J.G. Bakuckas and W.S. Johnson, "Implementation of thermal residual stresses in the analysis of fiber bridged matrix crack growth in titanium matrix composites", NASA TM 109082, February, 1994.

21. J.R. Calcaterra and S. Mall, "The effect of damage morphology on the residual strength degradation of SCS-6/Ti-15-3", Proceedings of the American Society for Composites' $13^{\text {ih }}$ Technical Conference on Composite Materials, September 21-23, 1998.

22. S.J. Covey, B.A. Lerch and N. Jayaraman, "Fiber volume fraction effects on fatigue crack growth in SiC/Ti-15-3 composite", Materials Science and Engineering, A200, 68-77 (1995). 
